OPEN ACCESS

Edited by:

Tom Crick,

Swansea University, United Kingdom

Reviewed by:

Nicos Souleles,

Cyprus University of Technology,

Cyprus

Ala'a B. Al-Tammemi,

University of Debrecen, Hungary

*Correspondence:

Sheng-Yi Wu

digschoo/@gmail.com

Specialty section: This article was submitted to

Digital Education,

a section of the journal

Frontiers in Education

Received: 03 March 2021

Accepted: 06 May 2021

Published: 28 May 2021

Citation:

Wu S-Y (2021) How Teachers Conduct Online Teaching During the COVID-19

Pandemic: A Case Study of Taiwan.

Front. Educ. 6:675434.

doi: 10.3389/feduc.2021.675434

\section{How Teachers Conduct Online Teaching During the COVID-19 Pandemic: A Case Study of Taiwan}

\author{
Sheng-Yi $W u^{*}$ \\ Department of Science Communication, National Pingtung University, Pingtung, Taiwan
}

Although online teaching has been encouraged for many years, the COVID-19 pandemic has promoted it on a large scale. During the COVID-19 pandemic, students at all levels (college, secondary school, and elementary school) were unable to attend school. To maintain student learning, most schools have adopted online teaching. Therefore, the purpose of this study was to explore the design of online teaching activities and online teaching processes adopted by teachers at all levels during the pandemic. Online questionnaires were administered to teachers in Taiwan who had conducted online teaching (including during the formal suspension of classes or simulation exercises) due to the pandemic. According to a quantitative analysis and lag sequential analysis, the instructional behaviors most frequently performed by teachers were roll calls, lectures with a presentation screen, in-class task (assignment) allocation, and whole-class synchronous video-/audio-based discussion. Thus, there were six common significant sequential behaviors among teachers at all levels that were categorized into the four instructional stages of identifying the teaching environment, teaching the class, discussing and evaluating learning effectiveness. College teachers reminded students of some matters first and then called the roll after the students went online. Secondary school teachers were more likely to arrange practical or experimental courses and to use synchronous and asynchronous interactive activities. Finally, elementary school teachers were more likely to use homemade videos and share their screens for teaching and to arrange a large variety of teaching interactions. The differences among colleges, secondary schools, and elementary schools were identified, and suggestions were made accordingly.

Keywords: COVID-19, e-learning, online teaching, lag sequential analysis (LSA), emergency remote education (ERE)

\section{INTRODUCTION}

Since 1990, Internet-based distance teaching has become a global trend, and software, hardware and educational training have been evolving. Nouns related to e-learning, such as online learning, distance teaching, digital learning, mobile learning and recent massive open online courses (MOOCs), have shown a trend of learning via the Internet. However, despite active promotion by governments, there are still many limitations to the online educational environment from teaching and learning perspectives (Meskhi et al., 2019; Sadeghi, 2019), such as the support of the administrative system, the establishment of a network bandwidth and teachers' willingness to record e-Learning materials. 
Since the first report of coronavirus disease 2019 (COVID-19) in Wuhan (China) in December 2019, COVID-19 has rapidly spread worldwide (Zhu et al., 2020). The World Health Organization (WHO) declared a public health emergency of international concern on January 30, 2020 and named the disease COVID-19 on February 11, 2020. On March 11, 2020, the WHO declared COVID-19 a global pandemic (Singhal, 2020; World Health Organization, 2020).

Due to the respiratory illness caused by COVID-19, many countries have suspended all types of face-to-face activities, including in-person education. The COVID-19 pandemic has forced many changes in most life domains to meet the repercussions of the pandemic control measures, and the education sector was no exception. In many countries, colleges, secondary schools and elementary schools have adopted the strategy of online education during the pandemic. As a result, teachers and students have had to quickly alter their teaching methods, regardless of whether they were experienced in and prepared for online education. Because of this situation, a proper term has appeared in the academic domain: emergency remote education.

Online education-related studies and models have been promoted for years (Sun and Chen, 2016). Before the COVID19 pandemic, most of these studies were focused on colleges, while teachers and students in elementary and secondary schools remained inexperienced in emergency remote education (Lestari and Gunawan, 2020). For example, Taiwan has promoted digital course certification at the university level for many years, and universities have also supported teachers in recording e-learning materials. Therefore, university teachers are more experienced in online teaching. However, in primary and secondary schools, digital teaching plays only a supplementary role. The preepidemic model is for students to go to classrooms. Therefore, teachers in primary and secondary schools have insufficient experience in switching to online teaching.

In response to COVID-19, schools at all levels needed an immediate shift towards online education, which can be both an opportunity and a challenge (Toquero, 2020). Therefore, some studies have been conducted to discuss emergency remote education during the COVID-19 pandemic. For example, Crawford et al. (2020) investigated 20 countries' responses to the COVID-19 epidemic. They pointed out that the response to higher education is diverse, including nonresponse, campus social isolation strategies, and rapid response to fully online courses. Watermeyer et al. (2020) reported a survey from 1,148 academics working in universities in the United Kingdom. They suggested that online migration is engendering significant dysfunctionality and disturbance to their pedagogical roles and their personal lives. Loima (2020) compared socio educational policies and arguments in Sweden and Finland during the COVID-19 pandemic. The results showed that Swedish and Finnish policy obscured mandates and restricted information. However, remote learning was successful in epidemiologic and curricular senses in Finnish. Basilaia and Kvavadze (2020) conducted a case study in Georgia. The Google Meet platform was implemented for online education with 950 students. The results indicated that the quick transition to the online form of education went successful and that gained experience can be used in the future. Putra et al. (2020) visited 10 websites in Indonesia to explore students' learning experiences during the COVID-19 pandemic. The results showed that student hardship in learning from home caused a lack of learning resources, such as not accessing the Internet and parents' ability to support their children's learning. In Cyprus, Souleles et al. (2020) believed that e-learning is not an add-on to existing teaching and learning practices and that disciplinary differences need to be considered. The provision of hurriedly set up workshops to enhance the skill gaps of teachers, although it is a necessary step, cannot replace the need for sustained training in both the pedagogical and technical areas. In Norway, Langford and Damsa (2020) discovered some phenomena, such as the Zoom revolution, a significant level of interactive online learning, innovations for involuntary teaching reform, collegial competence building and self-help, technological challenges and pedagogical insecurity. In Beijing, when the outbreak prevented people from going to school, the scholars of Peking University proposed the following five specific teaching strategies for online education in pandemic circumstances: 1) a high relevance between online instructional design and student learning; 2) the effective delivery of online instructional information; 3) adequate support provided by faculty and teaching assistants to students; 4) high-quality participation to improve the breadth and depth of students' learning; and 5) contingency plans to address unexpected incidents on online education platforms (Bao, 2020). In addition, many scholars in medical education have explored the challenges and future of online education in their own field. For example, Goh and Sandars (2020) indicated that major changes have been taking place in global medical education and that it is necessary to strengthen technological innovation to maintain teaching; they proposed that the use of artificial intelligence for adaptive learning and virtual reality might be future trends in medical education.

In addition to the abovementioned studies on overall education, there have been more studies that explore students' opinions during emergency remote education. Abbasi et al. (2020) reported that when students were unable to go to school because of the epidemic, they did not like online learning as much as face-to-face teaching. Thus, school administrative departments and teachers should take the necessary measures to improve online educational environments. Based on a survey of 77 medical students in their classroom situations, Agarwal and Kaushik (2020) argued that students believed that online courses altered their normal procedures, saved a large amount of time and made it easy for them to obtain teaching materials. The main barriers to learning were the number of participants and technical failures during class conversations. Owusu-Fordjour et al. (2020) investigated online learning among 214 college students and found that the pandemic had a negative effect on their learning because many of them were not used to learning effectively on their own. As most of the students in this region could not access the Internet and lacked the technical knowledge of Internet devices, the learning platforms that were used also posed a challenge for them. 
Most of the above studies on students' opinions focused on college education because college students' abilities for selfregulated learning in online education are better than those of primary and secondary students because of their age (Heo and Han, 2018). However, when the pandemic began, all schools faced the challenge of switching to emergency remote education. Some studies have explored learning issues in elementary and secondary schools during the outbreak. For example, Sintema (2020) noted that Zambian primary and secondary schools enabled teachers and students to have classes via mobile phones and tablets by implementing e-learning and smart revision portals while increasing the number of mobile devices available for use. The study found that these teaching and learning methods helped teachers deliver teaching materials and students to be capable of self-regulated learning during the pandemic. In addition, Fauzi and Khusuma (2020) surveyed 45 elementary school students and identified problems in implementing online teaching, including 1) the availability of facilities, 2) network and Internet usage, 3 ) the planning, implementation, and evaluation of learning, and 4) collaboration with parents. The authors expected that online learning would be helpful to teachers during the COVID-19 pandemic, but their results indicated poor outcomes of online learning, with $80 \%$ of teachers reporting that they felt dissatisfied with online education.

\section{STUDY OBJECTIVES}

According to the abovementioned studies on the COVID-19 pandemic, teachers and students were forced to conduct online education regardless of their level of preparation for it. Most of the recent studies have investigated students' feelings about online education and learning effectiveness, but there has been little discussion of teachers' design of teaching activities when they had to switch to online teaching due to the pandemic. Accordingly, this study explored how teachers designed their teaching activities when they switched to online teaching due to the pandemic or how they conducted online teaching in the form of exercises to provide a reference for the future promotion of online education. As a result, the first objective of this study is to discuss teachers' design of online teaching activity during the COVID-19 pandemic.

Moreover, our knowledge of teachers' online teaching activities is based on online teaching activities in normal conditions. In addition, teaching activity plans are sequential (Brown and Green, 2018). For example, Gagne's model of instructional design includes 1) gaining attention, 2) informing the learner of the objective, 3) stimulating the recall of prerequisite learning, 4) presenting the stimulus material, 5) providing learning guidance, 6) eliciting the performance, 7) providing feedback, 8) assessing the performance, and 9) enhancing retention and transfer (Khadjooi et al. (2011). The second objective of this study is to explore which activities were carried out first and last and the order of teachers' teaching activities. Thus, to understand the teaching activities adopted by teachers during the COVID-19 pandemic and the implementation of these teaching activities, this study used a lag sequential analysis to inform the discussion on this topic.

During the COVID-19 pandemic, students at all levels (college, secondary school and elementary school) were unable to attend school. Online teaching can continue to maintain learning activities when everyone is not going out. Therefore, to maintain students' learning, most schools have adopted online teaching. In addition, for students of different ages, e.g., colleges, secondary schools and elementary schools, the teaching behaviors taken by teachers will be different (Kennan et al., 2018). Understanding how teachers engage in online teaching behaviors at this emergency remote learning time can serve as a reference for the future promotion of e-learning. This study discusses teachers' design of online teaching activity at all levels during the pandemic. The study explores the following two research questions:

(1) What are the online teaching activities adopted by teachers due to the suspension of classroom teaching due to the COVID-19 pandemic? and

(2) What are the similarities and differences among teachers from colleges, secondary schools and elementary schools in the design of their online teaching activity processes?

\section{METHODS AND MATERIALS}

\section{Data Collection and Participants}

This study mainly investigates teachers who had conducted online education (including during the formal suspension of classes and simulation exercises) because of the pandemic. Convenience sampling was adopted. Although many courses might have been changed to online teaching at the time that the teachers answered the questions, the study questionnaire asked about the teaching activity design of only one course. Data were collected from May 20 to June 30, 2020, by using a web-based questionnaire with a cross-sectional design. A total of 270 teachers answered the questionnaires, and 223 of the responses were valid. There were 23 college teachers (10.3\%), 51 secondary school teachers $(22.9 \%)$ and 149 elementary school teachers $(66.8 \%)$.

\section{Instrument}

In this study, a questionnaire on online teaching activities was developed based on the research purpose and some studies (i.e., Nilson and Goodson, 2017; Trust and Pektas, 2018; Sharoff, 2019). The questionnaire consisted of three major parts, namely, basic data (sex male and female), age (below 30 years old, $31-40$ years old, $41-50$ years old, 51-60 years old and over 61 years old), the served school (college or university, middle or high school, and elementary school), the years of teaching experience, online teaching experience (Were you experienced in online teaching prior to the pandemic (frequently, occasionally and never), Why did you conduct online teaching? (already in use, class suspension due to 
medical diagnosis and simulation exercises), and in most cases, which of the following methods do you choose for online teaching?) and the teaching process (synchronous teaching, asynchronous teaching and blended teaching). According to the various online teaching platforms and systems used (e.g., Google Classroom, iCAN, iLMS, Microsoft Teams, Moodle, Sunnet LMS, Adobe Connect, Cisco WebEx, CyberLink U Meeting, Google Meet, Jitsi Meet, JoinNet, LINE Chat, Zoom, YouTube Live broadcast, Facebook Live broadcast and Zuvio), the teaching processes were analyzed, summarized and then divided into the 4 categories of teaching (A), learning interaction (B), learning effectiveness (C) and others (D). After the online teaching activity questionnaire was prepared, three experts in online college education, one elementary school teacher, and one online education administrator of the education agency were invited to assist in the review of the questionnaire. The survey questionnaire was refined according to the suggestions received through the experts' review. The instructional behaviors that comprise the teaching process are listed below.

\section{A Teaching}

A1 Lecturing-presentation screen.

A2 Lecturing-blackboard.

A3 Sharing a screen with computer software.

A4 Playing videos made by teachers.

A5 Playing videos made by others.

A6 Practical (experimental) demonstration.

\section{B Learning Interaction}

B1 Whole-class synchronous text-based discussion.

B2 Whole-class asynchronous text-based discussion.

B3 Whole-class synchronous video-/audio-based discussion.

B4 Whole-class asynchronous video-/audio-based discussion.

B5 Whole-group synchronous text-based discussion.

B6 Whole-group asynchronous text-based discussion.

B7 Whole-group synchronous video-/audio-based discussion.

B8 Whole-group asynchronous video-/audio-based discussion.

B9 Whole-class whiteboard interaction.

B10 Whole-group whiteboard interaction.

B11 Student self-practice.

B12 Operation by remote control.

B13 Data collection and collation.

\section{Learning Effectiveness}

C1 In-class study experience.

C2 In-class task (assignment) allocation.

C3 In-class online test.

$\mathrm{C} 4$ In-class online questionnaire.

C5 In-class peer evaluation.

C6 In-class work submission.

C7 In-class assignment/work report.

C8 After-class study experience.

C9 After-class task (assignment) allocation.

C10 After-class online test.

C11 After-class online questionnaire.
C12 After-class peer evaluation/voting.

C13 After-class work submission.

\section{Others}

D1 Roll call

D2 Inquiry about the status of hardware and software.

D3 Reminders of other noncourse matters.

D4 Others.

\section{Data Analysis}

In this study, descriptive statistics were used to analyze the basic data, the online teaching experience and the first research question. The second research question was analyzed through a lag sequential analysis (Bakeman and Gottman, 1997). Lag sequential analysis (Bakeman and Gottman, 1997) is used not only to explore a continuous sequence of behavioral coding categories (namely, an online teaching process) in which an initial behavioral coding category is followed by a subsequent category but also to visualize behavioral patterns. Researchers have mainly applied this method to the analysis of education issues. For example, Lin et al. (2020) developed a scaffolding-based collaborative problem-solving (CPS) learning environment to improve students' learning in CPS activities. According to the study results, the learning performance was significantly better for the scaffolding mind tool group than for the study sheet group, and the scaffolding mind tool group showed more diverse cognitive process transitions in their behavioral patterns. Zarzour et al. (2020) investigated the behavioral patterns of students by using eBooks on Facebook for learning. The experimental results indicated significant behavioral learning sequences and revealed that the behaviors of liking, commenting, and sharing posts with peers showed the most significant differences between the students with higher and lower engagement. Wang and Liu (2020) discussed teachers' current online teaching and students' interaction and collaborative knowledge construction. According to the results, the design and organization of learning materials and the facilitation of discourse promoted students' interaction, reduced the number of peripheral students, and supported students' collaborative knowledge construction.

The following were the five steps in the lag sequential analysis: 1) calculating the number of transitions among the behavioral codes to obtain the transition frequency table; 2) calculating the conditional probability of the transitions among the codes based on the above sequential frequency matrix to produce the sequential transition conditional probability; 3 ) calculating the expected value of the overall transition process among the codes based on the sequential frequency matrix; 4) verifying whether all sequences were significantly continuous one-by-one based on the Z-score values of the transition frequency calculated from the above three matrices (adjusted residuals table); and 5) drawing the sequence transition association diagram with nodes that represent all coding behaviors connected by arrows for further inferential analysis. 


\section{RESULTS AND DISCUSSION}

\section{Basic Data and Online Teaching Experience}

The Google online questionnaire was adopted in this study, and all questions must be answered to be valid. As shown in Table 1, a total of 223 valid questionnaires were collected in this study. In terms of sex, there were 100 males $(44.8 \%)$ and 123 females (55.2\%), and there was virtually no difference in the numbers of males and females. Therefore, this study is not affected by gender differences. Regarding age, there were 23 people (13.3\%) under 30 years old, 24 people $(10.8 \%)$ between 31 and 40 years, 57 people (25.6\%) between 41 and 50 years, 106 people $(47.5 \%)$ between 51 and 60 years, and 36 people (16.1\%) aged 61 years or over. Most of the respondents were between 41 and 60 years old. In the quartile of age, Q1 was 31-40 years, and Q2 (median) and Q3 were 41-50 years. Regarding the years of teaching experience, there were 12 teachers (5.4\%) with less than 1 year of service, 26 teachers $(11.7 \%)$ with $1-5$ years of service, 21 teachers $(9.4 \%)$ with $6-10$ years of service, 54 teachers $(24.2 \%)$ with $11-15$ years of service, 57 teachers (25.6\%) with 16-20 years of service, and 53 teachers $(23.8 \%)$ with more than 21 years of service. In the quartile of teaching experience, Q1 is 1-5 years, Q2 (median) is 16-20 years, and Q3 is more than 21 years. Most teachers were found to have many years of experience. At the school level, there were 23 college teachers $(10.3 \%), 51$ secondary school teachers (22.9\%), and 149 elementary school teachers (66.8\%). Thus, most of the respondents were elementary school teachers, followed by secondary school teachers.

Then, the study examined whether teachers were experienced in online teaching prior to the pandemic. Fourteen teachers (6.3\%) had frequently engaged in online teaching, 79 (35.4\%) had engaged in it occasionally, and 130 (58.3\%) had never engaged in it, which shows that more than half of the teachers had no experience in online teaching. As a result, the reason why online teaching had been adopted was explored. In total, 21 teachers had been teaching online prior to the pandemic (9.4\%), seven taught online due to a medical diagnosis (3.1\%), and 195 taught online as a part of simulation exercises (87.4\%); these findings show that the primary reason for switching to online teaching was simulation exercises, as the COVID-19 pandemic in Taiwan was well controlled. Regarding the modes frequently used in online teaching, 89 teachers (39.9\%) used synchronous teaching (teachers and students go online at the same time to carry out teaching and learning activities), 65 teachers $(29.1 \%)$ used asynchronous teaching (teachers upload teaching materials to the network platform, and students can watch them online within a specified time and carry out learning activities), and 69 teachers (30.9\%) used blended teaching (teaching and learning activities that combine both synchronous and asynchronous modes); thus, similar proportions of the teachers used the three teaching modes.

\section{Teaching Activities}

The 223 teachers who returned valid questionnaires had a total of 1,310 instructional behaviors, with an average of 5.87 instructional behaviors for each teacher. Table 2 shows the overall instructional behaviors, and the number and percentage of instructional behaviors in elementary schools, secondary schools, and colleges.

Overall, there were 329 data points (25.11\%) for teaching (A), 340 data points (25.95\%) for learning interaction (B), 383 data points (29.24\%) for learning effectiveness (C), and 258 data points (19.69\%) for others (D). The proportion of other instructional behaviors was similar to but slightly lower than the proportions of the remaining three teaching categories. Among the four teaching categories, the top four behaviors were roll call (D1) with 132 data points (10.08\%), lecturing with a presentation screen (A1) with 124 data points $(9.47 \%)$, in-class task (assignment) allocation (C2) with 104 data points (7.94\%), and whole-class synchronous video-/audio-based discussion (B3) with 103 data points (7.86\%). Thus, the most common behavior in each category was teaching behavior.

Then, the four teaching categories were analyzed from an overall perspective. In teaching (A), lecturing with a presentation screen (A1) was the most frequently used $(N=124,9.47 \%)$, followed by sharing a screen with computer software (A3) $(\mathrm{N}=$ $101,7.71 \%)$; this shows that most teachers frequently lectured with a presentation screen and shared their computer screens in online teaching. In learning interaction (B), whole-class synchronous video-/audio-based discussion (B3) was the most frequently used $(N=103,7.86 \%)$, followed by student selfpractice (B11) $(N=82,6.26 \%)$; this indicates that the teachers often conducted a whole-class synchronous discussion after teaching and allowed students to become familiar with the teaching content through their own practice. In addition, we also found that the teachers conducted more activities in entire classes than in groups. Although group learning is a common teaching activity in classroom teaching, in the online teaching environment, group interaction is rarely adopted by teachers because of the limitations imposed by the functional design of the learning platform or system. In learning effectiveness (C), the most common and second-most common instructional behaviors both concerned task (assignment) allocation, including class-task (assignment) allocation (C2) with 104 data points (7.94\%), and after-class task (assignment) allocation (C9) with 69 data points (5.27\%). By comparing all behaviors in class and after class, we found that the frequency of all in-class behaviors $(N=224$, $17.11 \%)$ was larger than the frequency of after-class behaviors $(N=159,12.14 \%)$, which suggests that the teachers mostly evaluated teaching effectiveness in class. Finally, in the other category (D), the most common mode was roll call (D1) with 132 data points $(10.08 \%)$, followed by inquiry about the status of hardware and software (D2) with 74 data points (5.65\%). These two items were important preclass activities in online teaching, although they do not take much time in classroom teaching.

Finally, the study explored the similarities and differences among colleges, secondary schools, and elementary schools in the four categories. In terms of teaching (A), we found that lecturing with a presentation screen (A1) was the most frequently used, followed by sharing a screen with computer software (A3), regardless of the learning stage. In terms of playing videos, we found that most videos played in colleges were made by teachers (A4), while the videos played in secondary and elementary schools were made by others (A5); this shows that college 
TABLE 1 | Participants' characteristics, including their online teaching experience.

\begin{tabular}{|c|c|c|c|}
\hline Variables & Attributes & $\mathbf{N}$ & $\%$ \\
\hline \multirow[t]{2}{*}{ Sex } & Male & 100 & 44.8 \\
\hline & Female & 123 & 55.2 \\
\hline \multirow[t]{5}{*}{ Age } & Below 30 years old & 23 & 13.3 \\
\hline & 31-40 years old & 24 & 10.8 \\
\hline & $41-50$ years old & 57 & 25.6 \\
\hline & $51-60$ years old & 106 & 47.5 \\
\hline & Over 61 years old & 36 & 16.1 \\
\hline \multirow[t]{6}{*}{ Years of teaching } & Under 1 year & 12 & 5.4 \\
\hline & $1-5$ years & 26 & 11.7 \\
\hline & $6-10$ years & 21 & 9.4 \\
\hline & $11-15$ years & 54 & 24.2 \\
\hline & 16-20 years & 57 & 25.6 \\
\hline & Over 21 years & 53 & 23.8 \\
\hline \multirow[t]{3}{*}{ School level } & College or university & 23 & 10.3 \\
\hline & Middle or high school & 51 & 22.9 \\
\hline & Elementary school & 149 & 66.8 \\
\hline \multirow[t]{3}{*}{ Were you experienced in online teaching prior to the pandemic? } & Frequently & 14 & 6.3 \\
\hline & Occasionally & 79 & 35.4 \\
\hline & Never & 130 & 58.3 \\
\hline \multirow[t]{3}{*}{ Why did you conduct online teaching? } & Already in use & 21 & 9.4 \\
\hline & Class suspension due to medical diagnosis & 7 & 3.1 \\
\hline & Simulation exercises & 195 & 87.4 \\
\hline \multirow[t]{3}{*}{ In most cases, which of the following ways do you choose for online teaching? } & Synchronous teaching & 89 & 39.9 \\
\hline & Asynchronous teaching & 65 & 29.1 \\
\hline & Blended teaching & 69 & 30.9 \\
\hline
\end{tabular}

teachers were more likely to make course videos for students to watch. Practical (experimental) demonstration (A6) was the least used. Although physical education courses and experimental courses still existed in the curriculum, the teachers seldom performed practice or experiments in the online teaching environment. In terms of learning interaction (B), we found that whole-class synchronous video-/audio-based discussion (B3) was the most frequently used, regardless of the learning stage. Moreover, unlike student practice (B11), whole-class synchronous text-based discussion (B1) was frequently used in colleges and secondary schools but was less frequently used in elementary schools, while whole-class whiteboard interaction (B9) was frequently used in elementary schools; this indicates that the teachers were more likely to arrange synchronous textbased discussion activities for older students. Finally, we found that data collection and collation (B13), a common activity in online teaching, was used in some secondary and elementary schools but not in colleges. In terms of learning effectiveness (C), we found that task (assignment) allocation (C2 and C9) was the most frequently used, regardless of the learning stage. Second, assignment and work reports (C7 and $\mathrm{C} 13$ ) were commonly used by college teachers for evaluation, online tests ( $\mathrm{C} 3$ and $\mathrm{C} 10)$ were commonly used by secondary and elementary teachers for evaluation, and there was almost no difference in their use between online teaching and the current situation in classroom teaching. In terms of the other category (D), based on the proportions of teachers who used the behaviors, we found that the most common behaviors were roll calls (D1), inquiries about the status of hardware and software (D2), and reminders of other noncourse matters (D3), regardless of the learning stage.

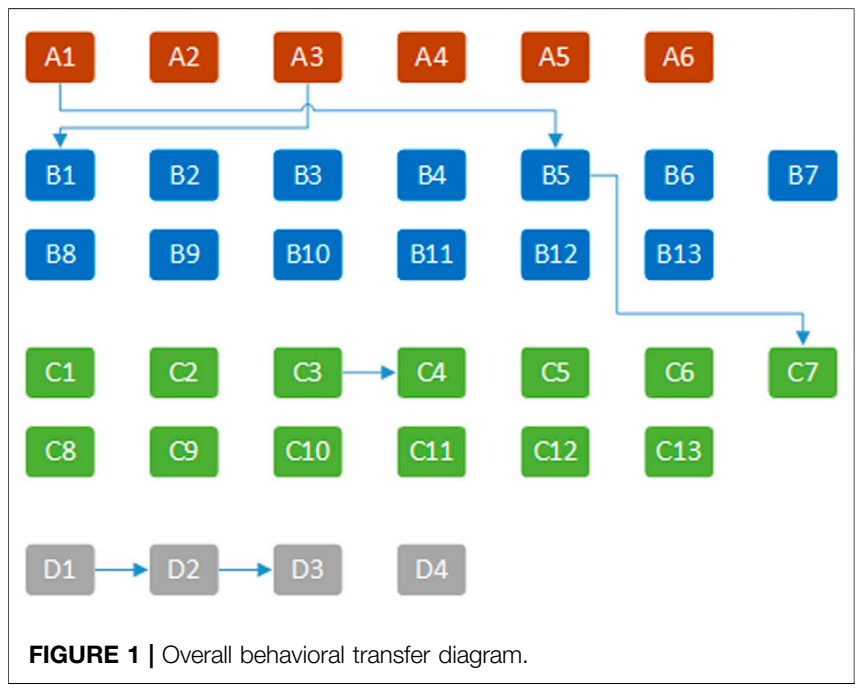

These behaviors were important for online teaching, but the questionnaire did not dedicate many questions to these behaviors.

\section{Teaching Behavioral Sequence}

During the lag sequential analysis, the adjusted residuals table was calculated, where the columns represent initial behaviors, and the rows signify the behaviors that occurred immediately after the behaviors listed in the columns. A Z-score greater than 1.96 indicated that the sequence was significant. In this study, there were 49, 58, and 104 significant behavioral sequences for colleges, secondary schools and elementary schools, respectively (as shown in the 
TABLE 2 | Number and percentage of various instructional behaviors.

\begin{tabular}{|c|c|c|c|c|c|c|c|c|}
\hline & \multicolumn{2}{|c|}{ Overall } & \multicolumn{2}{|c|}{ Colleges } & \multicolumn{2}{|c|}{$\begin{array}{c}\text { Secondary } \\
\text { schools }\end{array}$} & \multicolumn{2}{|c|}{$\begin{array}{c}\text { Elementary } \\
\text { schools }\end{array}$} \\
\hline & $\mathbf{N}$ & $\%$ & $\mathbf{N}$ & $\%$ & $\mathbf{N}$ & $\%$ & $\mathbf{N}$ & $\%$ \\
\hline \multicolumn{9}{|l|}{ A Teaching } \\
\hline A1 Lecturing - presentation screen & 124 & 9.47 & 14 & 10.53 & 27 & 9.75 & 83 & 9.22 \\
\hline A2 Lecturing - blackboard & 11 & 0.84 & 1 & 0.75 & 4 & 1.44 & 6 & 0.67 \\
\hline A3 Sharing a screen with computer software & 101 & 7.71 & 9 & 6.77 & 16 & 5.78 & 76 & 8.44 \\
\hline A4 Playing videos made by teachers & 18 & 1.37 & 6 & 4.51 & 4 & 1.44 & 8 & 0.89 \\
\hline A5 Playing videos made by others & 49 & 3.74 & 2 & 1.50 & 15 & 5.42 & 32 & 3.56 \\
\hline A6 Practical (experimental) demonstration & 26 & 1.98 & 2 & 1.50 & 6 & 2.17 & 18 & 2.00 \\
\hline Subtotal $(A)$ & 329 & 25.11 & 34 & 25.56 & 72 & 25.99 & 223 & 24.78 \\
\hline \multicolumn{9}{|l|}{ B Learning interaction } \\
\hline B1 Whole-class synchronous text-based discussion & 26 & 1.98 & 6 & 4.51 & 8 & 2.89 & 12 & 1.33 \\
\hline B2 Whole-class asynchronous text-based discussion & 19 & 1.45 & 0 & 0.00 & 7 & 2.53 & 12 & 1.33 \\
\hline B3 Whole-class synchronous video-/audio-based discussion & 103 & 7.86 & 9 & 6.77 & 21 & 7.58 & 73 & 8.11 \\
\hline B4 Whole-class asynchronous video-/audio-based discussion & 12 & 0.92 & 1 & 0.75 & 1 & 0.36 & 10 & 1.11 \\
\hline B5 Whole-group synchronous text-based discussion & 21 & 1.60 & 5 & 3.76 & 5 & 1.81 & 11 & 1.22 \\
\hline B6 Whole-group asynchronous text-based discussion & 4 & 0.31 & 1 & 0.75 & 0 & 0.00 & 3 & 0.33 \\
\hline B7 Whole-group synchronous video-/audio-based discussion & 10 & 0.76 & 3 & 2.26 & 1 & 0.36 & 6 & 0.67 \\
\hline B8 Whole-group asynchronous video-/audio-based discussion & 0 & 0.00 & 0 & 0.00 & 0 & 0.00 & 0 & 0.00 \\
\hline B9 Whole-class whiteboard interaction & 25 & 1.91 & 4 & 3.01 & 3 & 1.08 & 18 & 2.00 \\
\hline B10 Whole-group whiteboard interaction & 11 & 0.84 & 1 & 0.75 & 0 & 0.00 & 10 & 1.11 \\
\hline B11 Student self-practice & 82 & 6.26 & 5 & 3.76 & 18 & 6.50 & 59 & 6.56 \\
\hline B12 Operation by remote control & 10 & 0.76 & 1 & 0.75 & 2 & 0.72 & 7 & 0.78 \\
\hline B13 Data collection and collation & 17 & 1.30 & 0 & 0.00 & 4 & 1.44 & 13 & 1.44 \\
\hline Subtotal (B) & 340 & 25.95 & 36 & 27.07 & 70 & 25.27 & 234 & 26.00 \\
\hline \multicolumn{9}{|l|}{ C Learning effectiveness } \\
\hline C1 In-class study experience & 6 & 0.46 & 1 & 0.75 & 3 & 1.08 & 2 & 0.22 \\
\hline C2 In-class task (assignment) allocation & 104 & 7.94 & 12 & 9.02 & 25 & 9.03 & 67 & 7.44 \\
\hline C3 In-class online test & 58 & 4.43 & 3 & 2.26 & 14 & 5.05 & 41 & 4.56 \\
\hline C4 In-class online questionnaire & 8 & 0.61 & 1 & 0.75 & 2 & 0.72 & 5 & 0.56 \\
\hline C5 In-class peer evaluation & 3 & 0.23 & 0 & 0.00 & 0 & 0.00 & 3 & 0.33 \\
\hline C6 In-class work submission & 11 & 0.84 & 1 & 0.75 & 0 & 0.00 & 10 & 1.11 \\
\hline C7 In-class assignment/work report & 34 & 2.60 & 6 & 4.51 & 6 & 2.17 & 22 & 2.44 \\
\hline C8 After-class study experience & 4 & 0.31 & 3 & 2.26 & 1 & 0.36 & 0 & 0.00 \\
\hline C9 After-class task (assignment) allocation & 69 & 5.27 & 5 & 3.76 & 15 & 5.42 & 49 & 5.44 \\
\hline C10 After-class online test & 46 & 3.51 & 3 & 2.26 & 11 & 3.97 & 32 & 3.56 \\
\hline C11 After-class online questionnaire & 7 & 0.53 & 0 & 0.00 & 2 & 0.72 & 5 & 0.56 \\
\hline C12 After-class peer evaluation/voting & 4 & 0.31 & 1 & 0.75 & 0 & 0.00 & 3 & 0.33 \\
\hline C13 After-class work submission & 29 & 2.21 & 4 & 3.01 & 9 & 3.25 & 16 & 1.78 \\
\hline Subtotal (C) & 383 & 29.24 & 40 & 30.08 & 88 & 31.77 & 255 & 28.33 \\
\hline \multicolumn{9}{|l|}{ D Others } \\
\hline D1 Roll call & 132 & 10.08 & 12 & 9.02 & 32 & 11.55 & 88 & 9.78 \\
\hline D2 Inquiry about the status of hardware and software & 74 & 5.65 & 8 & 6.02 & 9 & 3.25 & 57 & 6.33 \\
\hline D3 Reminders of other noncourse matters & 45 & 3.44 & 3 & 2.26 & 3 & 1.08 & 39 & 4.33 \\
\hline D4 Others & 7 & 0.53 & 0 & 0.00 & 3 & 1.08 & 4 & 0.44 \\
\hline Subtotal (D) & 258 & 19.69 & 23 & 17.29 & 47 & 16.97 & 188 & 20.89 \\
\hline Total & 1,1310 & 100.00 & 133 & 100.00 & 277 & 100.00 & 900 & 100.00 \\
\hline
\end{tabular}

Supplementary Appendix). With the 36 instructional behaviors examined in this study, there were many significant behavioral sequences in each learning stage. To facilitate the discussion, the common significant behavioral sequences of colleges, secondary schools, and elementary schools were first extracted, and six significant behavioral sequences were identified in total. Second, to compare the differences among colleges, secondary schools, and elementary schools in the teaching process, significant behavioral sequences with Z-score values greater than five were discussed. There were 11,10 , and 15 significant behavioral sequences with Z-score values greater than five in colleges, secondary schools and elementary schools, respectively. The values shown in Table $\mathbf{3}$ are the Z-scores.

There were six common significant behavioral sequences in colleges, secondary schools, and elementary schools (Figure 1). 

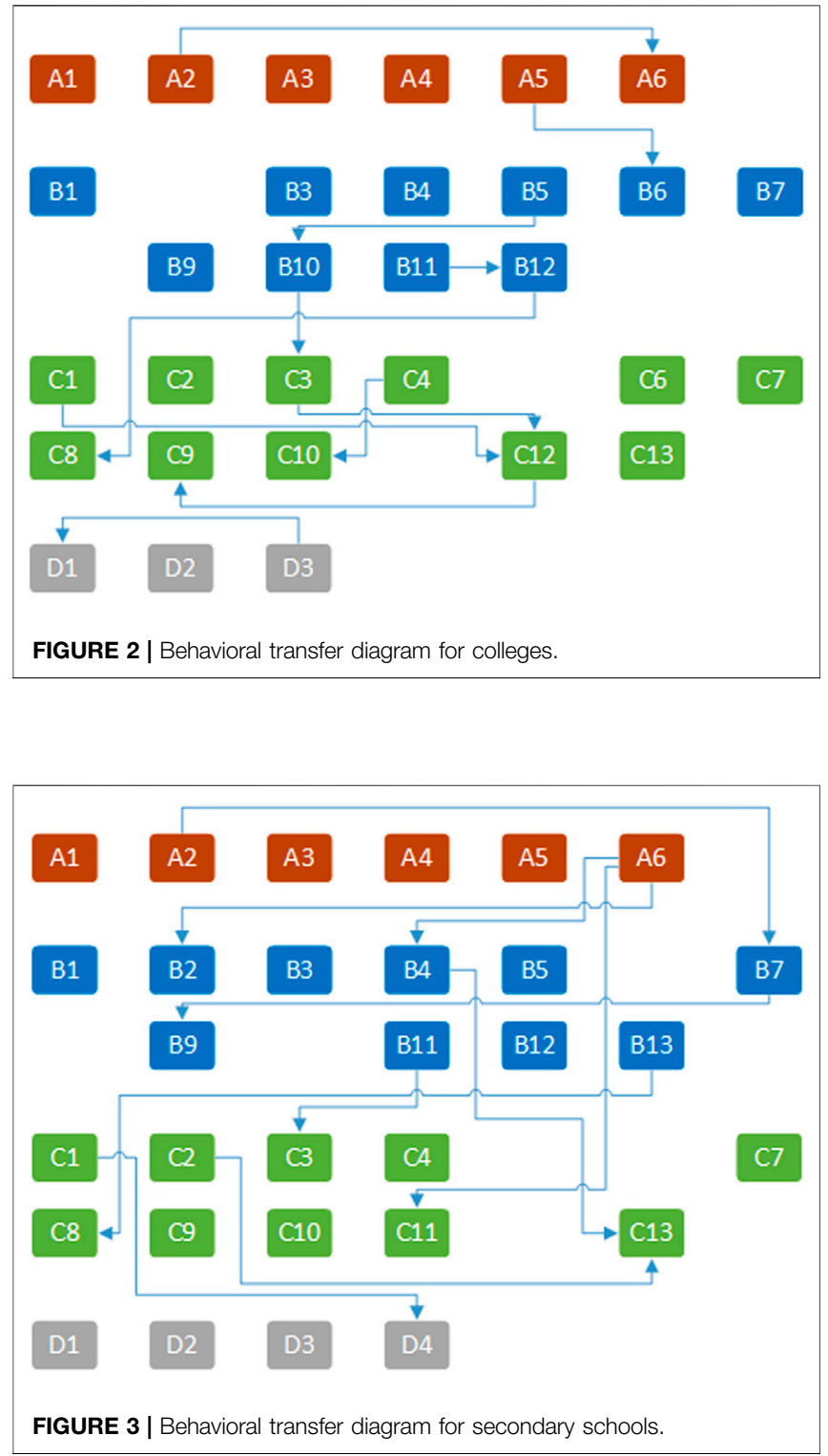

The six significant behavioral sequences were divided into four stages. The first stage included roll calls and the confirmation of an effective online teaching environment $(\mathrm{D} 1 \rightarrow \mathrm{D} 2)$. The next stage was teaching the class. The common teaching methods were presentation (A1) and screen sharing (A3). The next stage after teaching included text-based synchronous discussion $(\mathrm{A} 1 \rightarrow \mathrm{B} 5$ and $\mathrm{A} 3 \rightarrow \mathrm{B} 1)$. The final stage was the evaluation of learning effectiveness (B5 $\rightarrow \mathrm{C} 7$ and $\mathrm{C} 3 \rightarrow \mathrm{C} 4$ ). Overall, the common significant behavioral sequences in colleges, secondary schools and elementary schools, namely, identifying the teaching environment, teaching the class, discussing and evaluating learning effectiveness, were similar to the usual teaching processes.

Then, the characteristics of the teaching processes in colleges, secondary schools and elementary schools were compared based on the significant behavioral sequences with Z-score values greater than 5. To provide a basis for comparison, the abovementioned phases, i.e., 1) identifying the teaching environment, 2) teaching the class,

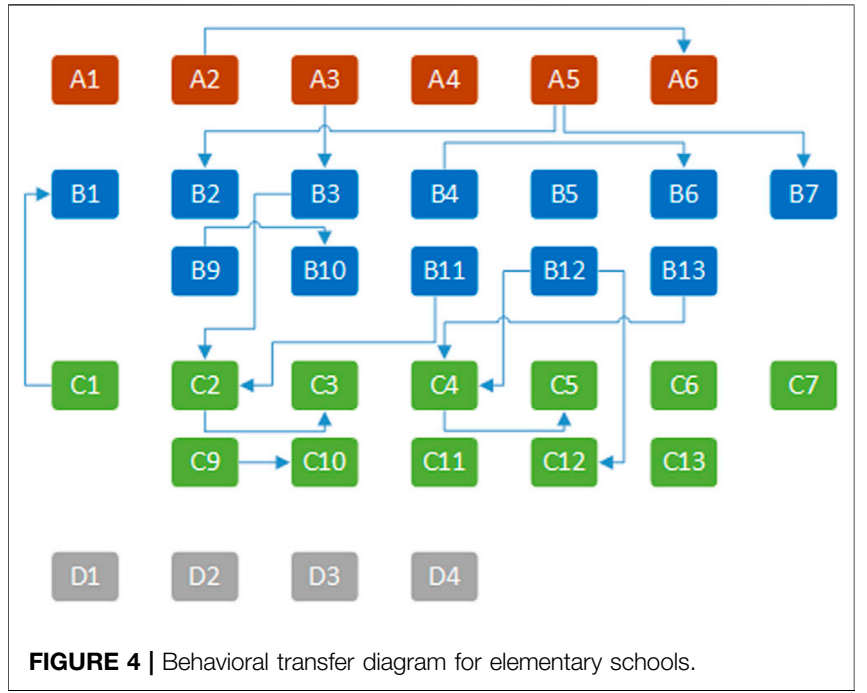

3) discussing and 4) evaluating learning effectiveness, were used for discussion. First, colleges (Figure 2) were more likely than secondary and elementary schools to use the following sequence: reminders for students of other noncurriculum matters (D3) $\rightarrow$ roll call (D1). This may be because, compared with secondary and elementary school teachers, college teachers are more likely to call roll after reminding students of matters during class and waiting for students to go online. This not only presents the actual situation of the physical classroom but also represents the teacher's differences in class management for students of different ages. In the teaching class stage, there was one common behavioral sequence between college teachers and elementary school teachers, namely, lecturing with a blackboard (A2) $\rightarrow$ practical (experimental) demonstration (A6). This may be because some experimental course teachers are used to lecture with a blackboard and directly filme experimental courses with cameras. In the discussing stage, college teachers engaged in less interactive learning behaviors than secondary and elementary school teachers, but most of their behaviors were carried out in groups $(\mathrm{A} 5 \rightarrow \mathrm{B} 6, \mathrm{~B} 5 \rightarrow \mathrm{B} 10, \mathrm{~B} 10 \rightarrow \mathrm{B} 3)$. Finally, in the evaluating learning effectiveness stage, college teachers had more diversified evaluation methods, including practice, tests, and questionnaires. Moreover, college teachers arranged many in-class and after-class evaluations $(\mathrm{C} 1 \rightarrow \mathrm{C} 12$, $\mathrm{C} 3 \rightarrow \mathrm{C} 12$ and $\mathrm{C} 4 \rightarrow \mathrm{C} 12$ ).

Second, in secondary schools (Figure 3), teachers were more likely to arrange practical or experimental courses and then carry out interactive activities such as discussions or questionnaires $(\mathrm{A} 6 \rightarrow \mathrm{B} 2$, $\mathrm{A} 6 \rightarrow \mathrm{B} 4$ and $\mathrm{A} 6 \rightarrow \mathrm{C} 11)$. In conducting interactive activities, teachers in secondary schools were more likely to use synchronous and asynchronous methods than teachers in colleges or elementary schools. Finally, in the stage of evaluating learning effectiveness, secondary school teachers had more diversified evaluation methods than college or elementary school teachers, including tests, questionnaires, and practice.

In elementary schools (Figure 4), teachers were more likely to use homemade videos and share their screens while teaching and then 
TABLE 3 | Significant behavioral sequences (similarities and differences Z-score>5).

\begin{tabular}{|c|c|c|c|}
\hline & Colleges & Secondary schools & Elementary schools \\
\hline Common significant behavioral sequences & $\begin{array}{l}\mathrm{A} 1 \rightarrow \mathrm{B} 5: 5.00 \\
\mathrm{~A} 3 \rightarrow \mathrm{B} 1: 2.70 \\
\mathrm{~B} 5 \rightarrow \mathrm{C} 7: 4.04 \\
\mathrm{C} 3 \rightarrow \mathrm{C} 4: 7.00 \\
\mathrm{D} 1 \rightarrow \mathrm{D} 2: 2.86 \\
\mathrm{D} 2 \rightarrow \mathrm{D} 3: 4.57\end{array}$ & & \\
\hline Differences in the significant behavioral sequences & $\begin{array}{l}\mathrm{A} 2 \rightarrow \mathrm{A} 6: 8.69 \\
\mathrm{~A} 5 \rightarrow \mathrm{B} 6: 8.66 \\
\mathrm{~B} 5 \rightarrow \mathrm{B} 10: 5.31 \\
\mathrm{~B} 10 \rightarrow \mathrm{C} 3: 7.05 \\
\mathrm{~B} 11 \rightarrow \mathrm{B} 12: 5.31 \\
\mathrm{~B} 12 \rightarrow \mathrm{C} 8: 7.05 \\
\mathrm{C} 1 \rightarrow \mathrm{C} 12: 6.06 \\
\mathrm{C} 3 \rightarrow \mathrm{C} 12: 7.00 \\
\mathrm{C} 4 \rightarrow \mathrm{C} 10: 7.05 \\
\mathrm{C} 12 \rightarrow \mathrm{C} 9: 5.39 \\
\mathrm{D} 3 \rightarrow \mathrm{C} 1: 7.00\end{array}$ & $\begin{array}{l}A 2 \rightarrow B 7: 8.96 \\
A 6 \rightarrow B 2: 5.22 \\
A 6 \rightarrow B 4: 7.25 \\
A 6 \rightarrow C 11: 5.03 \\
B 4 \rightarrow C 13: 5.91 \\
B 7 \rightarrow B 9: 10.42 \\
B 11 \rightarrow C 3: 5.82 \\
B 13 \rightarrow C 8: 8.96 \\
C 1 \rightarrow D 4: 5.89 \\
C 2 \rightarrow C 13: 5.00\end{array}$ & $\begin{array}{l}\mathrm{A} 2 \rightarrow \mathrm{A} 6: 5.89 \\
\mathrm{~A} 3 \rightarrow \mathrm{B} 3: 6.42 \\
\mathrm{~A} 5 \rightarrow \mathrm{B} 2: 7.52 \\
\mathrm{~A} 5 \rightarrow \mathrm{B} 7: 6.47 \\
\mathrm{~B} 3 \rightarrow \mathrm{C} 2: 5.82 \\
\mathrm{~B} 4 \rightarrow \mathrm{B} 6: 5.72 \\
\mathrm{~B} 9 \rightarrow \mathrm{B} 10: 6.76 \\
\mathrm{~B} 11 \rightarrow \mathrm{C} 2: 6.52 \\
\mathrm{~B} 12 \rightarrow \mathrm{C} 4: 5.27 \\
\mathrm{~B} 12-\mathrm{C} 12: 6.90 \\
\mathrm{~B} 13 \rightarrow \mathrm{C} 4: 7.73 \\
\mathrm{C} 1 \rightarrow \mathrm{B} 1: 6.45 \\
\mathrm{C} 2 \rightarrow \mathrm{C} 3: 5.51 \\
\mathrm{C} 4 \rightarrow \mathrm{C} 5: 8.22 \\
\mathrm{C} 9 \rightarrow \mathrm{C} 10: 5.14\end{array}$ \\
\hline
\end{tabular}

conduct discussions $(\mathrm{A} 3 \rightarrow \mathrm{B} 3, \mathrm{~A} 5 \rightarrow \mathrm{B} 2, \mathrm{~A} 5 \rightarrow \mathrm{B} 7)$. The teaching interactions arranged by elementary school teachers were diversified, and discussions containing audio and text were conducted with synchronous and asynchronous methods. Elementary school teachers, similar to college and secondary school teachers, used a variety of evaluation methods. In addition, elementary school teachers arranged many in-class evaluations, and after-class assignments, which is similar to general classroom teaching.

\section{DISCUSSION AND CONCLUSION}

During the COVID-19 pandemic, students at all levels (colleges, secondary schools, and elementary schools) were unable to attend school, and most schools switched to online teaching. To understand the design of online teaching activities among teachers at all levels, online questionnaires were adopted in this study to investigate teachers in Taiwan who had conducted online teaching due to the pandemic. There were 223 valid questionnaires.

The first objective was to explore teachers' online teaching activities when classroom teaching was suspended due to COVID-19. Based on the results of the frequencies of behaviors in the teaching, learning interaction, learning effectiveness and other categories, the top four instructional behaviors were roll calls, lecturing with a presentation screen, in-class task (assignment) allocation and whole-class synchronous video-/audio-based discussion. Then, the study explored the similarities and differences among colleges, secondary schools, and elementary schools in the four categories. In terms of teaching, lecturing with a presentation screen was the most frequently used, regardless of the learning stage. In terms of playing videos, most videos played in colleges were made by teachers, while most videos played in secondary and elementary schools were made by others. In terms of learning interaction, we found that whole-class synchronous video-/ audio-based discussion was the most frequently used, regardless of the learning stage. In addition, teachers' arrangement of synchronous text-based discussions depended on the learning level. In terms of learning effectiveness, task (assignment) allocation was the most frequent behavior, regardless of the learning stage. Second, assignments and work reports were commonly used by college teachers for evaluation, while teachers in secondary and elementary schools were more likely to use online tests for evaluation. Finally, in terms of the other category, we found that roll calls and inquiries about the learning environment, such as the status of hardware and software, were necessary for online teaching, regardless of the learning stage.

Overall, more time was spent on roll calls and inquiries about the status of hardware and software in online teaching than in classroom teaching. This means that teachers' technical capabilities for online teaching, students' familiarity with digital platforms, and the software and hardware assistance provided by the school's information center will all affect the quality of e-learning. Moreover, in terms of teaching, interaction and evaluation, the arrangement of these activities among teachers at all levels was slightly different from the arrangement of these activities in classroom teaching, and appropriate teaching activities could be designed according to the online teaching environment. Despite the limitations of online teaching platforms, online learning activities can still be carried out.

The second objective of this study was to explore the similarities and differences among college, secondary school and elementary school teachers in the design of the online teaching activity process. According to the sequential behavioral analysis, the common significant behavioral 
sequences of colleges, secondary school and elementary schools were divided into 1) roll calls and identification of the teaching environment, 2) teaching through presentation and screen demonstration, 3) synchronous text-based discussion, and 4) an effectiveness evaluation. Overall, the common significant behavioral sequences of colleges, secondary schools and elementary schools were similar to the usual teaching processes. In terms of the characteristics, some college teachers reminded students of some matters first and then called the roll after students went online. During class, some teachers in experimental or practical courses were used to lecture with a blackboard, and directly filme experimental courses with cameras. Moreover, college teachers engaged in less interactive learning behaviors, but most of their behaviors were carried out in groups. Second, secondary school teachers were more likely to arrange practical or experimental courses and to use synchronous and asynchronous interactive activities. Finally, elementary school teachers were more likely to use homemade videos and share their screens for teaching and to arrange a large variety of teaching interactions; in addition, discussions containing audio and text were conducted with both synchronous and asynchronous methods.

Overall, colleges, secondary schools, and elementary schools had common significant sequential behaviors, including roll calls and the identification of the teaching environment, teaching through presentation and screen sharing, synchronous textbased discussion and an effectiveness evaluation. Moreover, college, secondary, and elementary school teachers had similar characteristics in the design of their teaching activity processes. In addition to these similar characteristics, college, secondary, and elementary school teachers also have some different characteristics. These different characteristics show that teachers at different stages of learning vary in their teaching strategies. These differences, in addition to showing the current teaching situation, can also provide scholars with information for related follow-up research.

According to the conclusions generated based on the descriptive analysis and lag sequential analysis, the following suggestions can be made.

(1) Despite the small proportion of online practical and experimental courses, as evidenced by the observed online instructional behaviors, such courses are arranged in classroom teaching. It is suggested that when relevant, teachers should consider in advance how to respond to challenges in implementing practical and experimental courses in online teaching.

(2) Discussion is more important in the online teaching environment than in general classroom teaching ( $\mathrm{Wu}$, 2016). This study found that whole-class synchronous video-/audio-based discussion was the most frequently used method. Thus, whether activities are conducted as a class or in groups and whether synchronous or asynchronous discussion is used, teachers should improve the online discussion layout and their online leadership skills (Tseng et al., 2019).

(3) In classroom teaching, problem-based learning (PBL) courses are often arranged, which require students to collect and collate data through the Internet (Dolmans et al., 2016). However, in this study, the rate of data collection and collation was low, even in the online education environment, but the activities of data collection and collation in the online learning environment are more suitable for adoption. Therefore, it is suggested that teachers should design activities of data collection and collation for more diversified teaching activities.

(4) Due to the pandemic, people have been restricted in their ability to leave home. Therefore, in addition to the synchronous activities in class during teaching time, it is suggested that teachers arrange after-class asynchronous activities so that students can carry out learning activities when they cannot go out.

(5) In classroom teaching, it does not take much time to call roll or manage hardware and software. However, the two behaviors are important in the online teaching environment. Thus, both teachers and learning platforms or system developers should think about how to reduce the time spent on roll calls and the management of hardware and software.

In terms of the research limitations and suggestions for future studies, this study took Taiwan's teachers as an example; it is suggested that cross-country comparisons be carried out in future studies. Second, this study mainly discussed the situations, similarities and differences of colleges, secondary schools and elementary schools in the teaching activities and processes affected by the pandemic. However, teaching activities are also influenced by the course that is being taught. Thus, it is suggested that future researchers base their discussions on various types of courses. Finally, teachers' preparation for online teaching affects the quality of online education (Hung, 2016), which was not analyzed in this study. Therefore, it is suggested that future researchers compare the differences in teachers' experiences with online teaching.

\section{DATA AVAILABILITY STATEMENT}

The raw data supporting the conclusions of this article will be made available by the authors, without undue reservation.

\section{AUTHOR CONTRIBUTIONS}

The author contributed to the conception of the idea, implementing and analyzing the experimental results, and writing the manuscript.

\section{SUPPLEMENTARY MATERIAL}

The Supplementary Material for this article can be found online at: https://www.frontiersin.org/articles/10.3389/feduc.2021.675434/ full\#supplementary-material 


\section{REFERENCES}

Abbasi, S., Ayoob, T., Malik, A., and Memon, S. I. (2020). Perceptions of Students Regarding E-Learning during Covid-19 at a Private Medical College. Pak J. Med. Sci. 36, S57-S61. doi:10.12669/pjms.36.COVID19-S4.2766

Agarwal, S., and Kaushik, J. S. (2020). Student's Perception of Online Learning during COVID Pandemic. Indian J. Pediatr. 87 (7), 554. doi:10.1007/s12098020-03327-7

Bakeman, R., and Gottman, J. M. (1997). Observing Interaction: An Introduction to Lag Sequential Analysis. 2nd ed. United Kingdom: Cambridge University Press. doi:10.1017/cbo9780511527685

Bao, W. (2020). COVID -19 and Online Teaching in Higher Education: A Case Study of Peking University. Hum. Behav Emerg Tech 2 (2), 113-115. doi:10. 1002/hbe2.191

Basilaia, G., and Kvavadze, D. (2020). Transition to Online Education in Schools during a SARS-CoV-2 Coronavirus (COVID-19) Pandemic in Georgia. Pedagogical Res. 5 (4), 1-9. doi:10.29333/pr/7937

Brown, A. H., and Green, T. D. (2018). Beyond Teaching Instructional Design Models: Exploring the Design Process to advance Professional Development and Expertise. J. Comput. High Educ. 30 (1), 176-186. doi:10.1007/s12528-0179164-y

Crawford, J., Butler-Henderson, K., Rudolph, J., Malkawi, B., Glowatz, M., Burton, R., and Lam, S. (2020). COVID-19: 20 Countries' Higher Education Intraperiod Digital Pedagogy Responses. J. Appl. Learn. Teach. 3 (1), 1-20. doi:10. 37074/jalt.2020.3.1.7

Dolmans, D. H. J. M., Loyens, S. M. M., Marcq, H., and Gijbels, D. (2016). Deep and Surface Learning in Problem-Based Learning: a Review of the Literature. Adv. Health Sci. Educ. 21 (5), 1087-1112. doi:10.1007/s10459-015-9645-6

Fauzi, I., and Sastra Khusuma, I. H. (2020). Teachers' Elementary School in Online Learning of COVID-19 Pandemic Conditions. J. Iqra. 5 (1), 58-70. doi:10. 25217/ji.v5i1.914

Goh, P.-S., and Sandars, J. (2020). A Vision of the Use of Technology in Medical Education after the COVID-19 Pandemic. MedEdPublish 9, 1. doi:10.15694/ mep.2020.000049.1

Heo, J., and Han, S. (2018). Effects of Motivation, Academic Stress and Age in Predicting Self-Directed Learning Readiness (SDLR): Focused on Online College Students. Educ. Inf. Technol. 23 (1), 61-71. doi:10.1007/s10639-0179585-2

Hung, M.-L. (2016). Teacher Readiness for Online Learning: Scale Development and Teacher Perceptions. Comput. Educ. 94, 120-133. doi:10.1016/j.compedu. 2015.11.012

Kennan, S., Bigatel, P., Stockdale, S., and Hoewe, J. (2018). The (Lack of) Influence of Age and Class Standing on Preferred Teaching Behaviors for Online Students. Online Learn. 22 (1), 163-181. doi:10.24059/olj.v22i1.1086

Khadjooi, K., Rostami, K., and Ishaq, S. (2011). How to Use Gagne's Model of Instructional Design in Teaching Psychomotor Skills. Gastroenterol. Hepatol. Bed Bench 4 (3), 116-119.

Langford, M., and Damsa, C. (2020). Online Teaching in the Time of COVID-19: Academic Teachers' Experiences in Norway. Centre for Experiential Legal Learning (CELL), University of Oslo.

Lestari, P. A. S., and Gunawan, G. (2020). The Impact of Covid-19 Pandemic on Learning Implementation of Primary and Secondary School Levels. Indonesian J. Elem. Child. Educ. 1 (2), 58-63.

Lin, P.-C., Hou, H.-T., and Chang, K.-E. (2020). The Development of a Collaborative Problem Solving Environment that Integrates a Scaffolding Mind Tool and Simulation-Based Learning: an Analysis of Learners' Performance and Their Cognitive Process in Discussion. Interactive Learn. Environments. doi:10.1080/10494820.2020.1719163

Loima, J. (2020). Socio-Educational Policies and Covid-19 - A Case Study on Finland and Sweden in the Spring 2020. Int. J. Edu. Literacy. Studies. 8 (3), 59-75. doi:10.7575/aiac.ijels.v.8n.3p.59

Meskhi, B., Ponomareva, S., and Ugnich, E. (2019). E-learning in Higher Inclusive Education: Needs, Opportunities and Limitations. Int. J. Edu. Manag. 33 (3), 424-437. doi:10.1108/IJEM-09-2018-0282
Nilson, L. B., and Goodson, L. A. (2017). Online Teaching at its Best: Merging Instructional Design with Teaching and Learning Research. Hoboken, NJ: John Wiley \& Sons.

Owusu-Fordjour, C., Koomson, C. K., and Hanson, D. (2020). The Impact of Covid-19 on Learning-The Perspective of the Ghanaian Student. Eur. J. Educ. Stud. 7 (3), 88-101. doi:10.5281/zenodo.3753

Putra, P., Liriwati, F. Y., Tahrim, T., Syafrudin, S., and Aslan, A. (2020). The Students Learning from home Experiences during Covid-19 School Closures Policy in Indonesia. J. Iqra. 5 (2), 30-42. doi:10.25217/ji.v5i2.1019

Sadeghi, M. (2019). A Shift from Classroom to Distance Learning: Advantages and Limitations. Int. J. Res. English. Edu. 4 (1), 80-88. doi:10.29252/ijree.4.1.80

Sharoff, L. (2019). Creative and Innovative Online Teaching Strategies: Facilitation for Active Participation. Jeo 16 (2), 2. doi:10.9743/jeo.2019.16.2.9

Singhal, T. (2020). A Review of Coronavirus Disease-2019 (COVID-19). Indian J. Pediatr. 87 (4), 281-286. doi:10.1007/s12098-020-03263-6

Sintema, E. J. (2020). E-learning and Smart Revision Portal for Zambian Primary and Secondary School Learners: A Digitalized Virtual Classroom in the COVID-19 Era and beyond. Aquademia, 4(2), ep20017. doi:10.29333/aquademia/8253

Souleles, N., Laghos, A., and Savva, S. (2020). "From Face-To-Face to Online: Assessing the Effectiveness of the Rapid Transition of Higher Education Due to the Coronavirus Outbreak," in 15th International Technology, Education and Development Conference, Cyprus, November 9-10, 2020. doi:10.21125/iceri. 2020.0274

Sun, A., and Chen, X. (2016). Online Education and its Effective Practice: A Research Review. JITE:Research 15, 157-190. doi:10.28945/3502

Toquero, C. M. (2020). Challenges and Opportunities for Higher Education amid the COVID-19 Pandemic: The Philippine Context. Pedagogical Res. 5 (4), em0063. doi:10.29333/pr/7947

Trust, T., and Pektas, E. (2018). Using the ADDIE Model and Universal Design for Learning Principles to Develop an Open Online Course for Teacher Professional Development. J. Digital Learn. Teach. Educ. 34 (4), 219-233. doi:10.1080/21532974.2018.1494521

Tseng, H., Yi, X., and Yeh, H.-T. (2019). Learning-related Soft Skills Among Online Business Students in Higher Education: Grade Level and Managerial Role Differences in Self-Regulation, Motivation, and Social Skill. Comput. Hum. Behav. 95, 179-186. doi:10.1016/j.chb.2018.11.035

Wang, Y., and Liu, Q. (2020). Effects of Online Teaching Presence on Students' Interactions and Collaborative Knowledge Construction. J. Comput. Assist. Learn. 36 (3), 370-382. doi:10.1111/jcal.12408

Watermeyer, R., Crick, T., Knight, C., and Goodall, J. (2020). COVID-19 and Digital Disruption in UK Universities: Afflictions and Affordances of Emergency Online Migration. High Educ. (Dordr) 81, 623-641. doi:10.1007/s10734-020-00561-y

World Health Organization (2020). Coronavirus Disease (COVID-2019) Situation Reports (Situation report - 51). Available at: www.who.int/emergencies/ diseases/novel-coronavirus-2019/situation-reports.

Wu, S.-Y. (2016). The Effect of Teaching Strategies and Students' Cognitive Style on the Online Discussion Environment. Asia-pacific Edu Res. 25 (2), 267-277. doi:10.1007/s40299-015-0259-9

Zarzour, H., Bendjaballah, S., and Harirche, H. (2020). Exploring the Behavioral Patterns of Students Learning with a Facebook-Based E-Book Approach. Comput. Educ. 156, 103957. doi:10.1016/j.compedu.2020.103957

Zhu, N., Zhang, D., Wang, W., Li, X., Yang, B., Song, J., et al. (2020). A Novel Coronavirus from Patients with Pneumonia in China, 2019. N. Engl. J. Med. 382, 727-733. doi:10.1056/NEJMoa2001017

Conflict of Interest: The author declares that the research was conducted in the absence of any commercial or financial relationships that could be construed as a potential conflict of interest.

Copyright $\odot 2021 \mathrm{Wu}$. This is an open-access article distributed under the terms of the Creative Commons Attribution License (CC BY). The use, distribution or reproduction in other forums is permitted, provided the original author(s) and the copyright owner(s) are credited and that the original publication in this journal is cited, in accordance with accepted academic practice. No use, distribution or reproduction is permitted which does not comply with these terms. 